\title{
Entre las visiones patrimonialistas y los derechos humanos: Reflexiones sobre restitución y repatriación en Argentina y Uruguay
}

\section{Gustavo Verdesio}

\section{(2) OpenEdition \\ Journals}

Electronic version

URL: http://journals.openedition.org/corpusarchivos/989

DOI: $10.4000 /$ corpusarchivos.989

ISSN: 1853-8037

\section{Publisher}

Diego Escolar

\section{Electronic reference}

Gustavo Verdesio, «Entre las visiones patrimonialistas y los derechos humanos: Reflexiones sobre restitución y repatriación en Argentina y Uruguay », Corpus [En línea], Vol 1, No 1 | 2011, Publicado el 30 junio 2011, consultado el 19 abril 2019. URL : http://journals.openedition.org/corpusarchivos/989 ; DOI : 10.4000/corpusarchivos.989

This text was automatically generated on 19 April 2019.

Licencia Creative Commons: Atribución-NoComercial 2.5 Argentina (CC BY-NC 2.5 AR) 


\title{
Entre las visiones patrimonialistas y los derechos humanos: Reflexiones sobre restitución y repatriación en Argentina y Uruguay
}

\author{
Gustavo Verdesio
}

En las Américas, la restitución de restos humanos pertenecientes a individuos que formaron parte de los diversos pueblos originarios que poblaron (y pueblan) ese vasto continente, es un tema que genera mucha tensión, cuando no irritación, entre algunos profesionales del estudio de la alteridad, sea ésta presente o pasada. De hecho, la legislación existente en Estados Unidos, por ejemplo, surgió de un desacuerdo, de una ausencia de consenso entre, por un lado, los practicantes de la arqueología y la antropología biológica y, por el otro, las comunidades de pueblos originarios.

Dicho sea esto como recordatorio, porque en el tratamiento de este problema se tiende a olvidar que la legislación se ha aprobado para proteger a los indígenas de las prácticas disciplinarias que violaron (y en ocasiones continúan violando) algunos de sus derechos. En otras palabras, lo que se olvida generalmente es que este tipo de legislación pertenece al dominio de los derechos humanos y que, a través de ella, se intenta garantizar un tratamiento igualitario a los restos humanos para todos los sectores de la población (Watkins 2004:65). En Estados Unidos, por ejemplo, NAGPRA (como se conoce a la ley sobre protección de las tumbas y sobre la repatriación de los restos humanos indígenas de ese país) tuvo como cometido dar fin al tratamiento desigual recibido, en estos temas, por los indígenas (muertos y vivos), a manos de los burócratas del Estado, el Ejército, y los científicos (sin ir más lejos, el mismo Boas - ver Thomas 2000 para una historia de las injusticias que sufrieron los indígenas a manos de esos actores) de la sociedad dominante. Esta situación no es exclusiva de los Estados Unidos: en otras partes, por ejemplo en la Argentina, también el Ejército y algunos prominentes miembros de la comunidad científica (por ejemplo, Francisco Pascasio Moreno), generaron procesos similares que 
llevaron a situaciones en las que, por un lado, se afectó la sensibilidad, y por el otro, se violaron algunos derechos básicos de importantes cantidades de sujetos pertenecientes a las diversas comunidades de pueblos originarios a lo largo y a lo ancho del territorio de ese país. El estudio de las sociedades indígenas tanto del pasado como del presente a través de sus restos y de su cultura material, está basado en una objetivización de lo indígena, en una deshumanización que tiene varias causas históricas que ya han sido estudiadas, como por ejemplo la transformación que se produce en la forma en que la medicina empieza a percibir el cuerpo humano en el siglo XVIII francés, época y lugar en que se convierte en dato, en objeto de estudio, en espécimen para la observación. En esa época, puede decirse que la mira-da médica redefine el cuerpo como algo legible y mensurable (Bieder 2000:20).

Pero tiene, también, una causa más concreta que se relaciona con las narrativas de la Nación y que Mariela E. Rodríguez llama, en su tesis doctoral, la patrimonialización de los cuerpos y de la cultura material indígenas (Rodríguez 2010:382-412). Esa patrimonialización consiste, entre otras cosas, en poner en juego una serie de "dispositivos hegemónicos patrimonializadores" (para decirlo en términos de la ya citada Rodríguez) que convierten lo indígena en objetos de colección, de estudio o de patrimonio para enriquecer el acervo de la nación. Son dispositivos como el discurso jurídico aquellos que convierten a los muertos en bienes o cosas, como bien señala Rodríguez (p. 386). Y es la propia ley de patrimonio vigente la que sostiene que los restos humanos indígenas se consideran bienes patrimoniales de la nación. Pero esto va en contra de una tendencia general reciente en la legislación argentina, que ha hecho grandes progresos con relación a los derechos que asisten a los pueblos originarios.

Desde 1994, cuando la Constitución de la República les reconoció a los pueblos originarios su status de preexistentes a la conformación del Estado, se les están reconociendo una serie de derechos que antes les estuvieron vedados. Uno de esos derechos adquiridos recientemente es el de pedir la restitución de los restos humanos de sus ancestros que están aún en posesión de museos y otras instituciones. La ley Nº 25.517 del 2001 así lo establece -ley que según lo declarado y dispuesto por la Presidenta Cristina Fernández de Kirchner el 20 de mayo pasado, será reglamentada a la brevedad, a fin de que pueda, por fin, comenzar a aplicarse como es debido- cuando dice en su primer artículo: "Los restos mortales de aborígenes, cualquiera fuera su característica étnica, que formen parte de museos y/o colecciones públicas o privadas, deberán ser puestos a disposición de los pueblos indígenas y/o comunidades de pertenencia que lo reclamen".

5 Sin embargo, la ley de patrimonio $\mathrm{N}^{\circ} 25.743$ (del 2003) y su reglamentación por el decreto 1022 del 2004, van en una dirección que no vacilamos en catalogar como contraria al clima jurídico imperante hoy en la nación con relación a los pueblos originarios y sus reclamos. En esas leyes se sigue el espíritu del decreto 211 de 1922, que reglamentaba a la ley 9080 de 1913, que declara patrimonio nacional a los yacimientos antropológicos y paleo-antropológicos, que son definidos como: "todo lugar donde existen restos humanos de indígenas, anteriores o posteriores al descubrimiento de América" y "todo lugar donde existen restos de fauna o flora fósiles y restos humanos o de industria humana, de épocas geológicas anteriores a la presente". Esta consideración de los restos humanos de los ancestros de los indígenas de hoy como pertenecientes al patrimonio nacional -es decir, como bienes patrimoniales - va a contrapelo, como decía, de la tendencia establecida por la legislación citada en el párrafo anterior. A esto hay que sumarle que, como bien señala Endere, la ley $\mathrm{N}^{\circ} 25.743$ no tiene en absoluto en cuenta a las comunidades indígenas ni 
distingue "entre sitios arqueológicos ubicados en tierras de una comunidad indígena y los que se encuentran en propiedades privadas" (Endere et al. 2010:280), lo cual constituye un franco retroceso con relación a la legislación que se venía aprobando en el país.

6 Una legislación de este tipo, al ignorar olímpicamente otras normas del sistema jurídico, pierde de vista que los aspectos patrimoniales deben estar subordinados a los derechos humanos: si se dispone a voluntad, en nombre del Estado y el patrimonio nacional, de los restos humanos de indígenas del pasado emparentados con los indígenas del presente, se está vulnerando uno de los derechos más básicos del individuo: el de disponer de los restos de sus ancestros - garantizado, como ya vimos, por la ley de restitución del año 2001.

7 Estoy hablando de los aspectos jurídicos del complejo problema de la restitución de restos humanos porque es la manifestación más visible, más vinculante y coercitiva de las soluciones ensayadas para resolverlo. Sin embargo, soy plenamente consciente de que una discusión meramente jurídica del problema, como bien señala Mariela E. Rodriguez en su ya citada tesis doctoral, en realidad empobrece el análisis al dejar de lado, conscientemente, los aspectos culturales de la cuestión (p. 398). En otras palabras, al limitarnos a discutir los aspectos jurídicos de este tema, perdemos inexorablemente de vista ese mundo, ese universo de sentido forjado y vivido por los pueblos originarios - un mundo que la ciencia y las burocracias estatales han estudiado, sí, pero sin respetarlo, a lo largo de la historia independiente de los Estados-nación de las Américas. Esas comunidades del presente han heredado ciertas formas de ver el mundo que son necesarias para decidir, hoy en día, qué hacer con esos muertos en posesión de los museos y otras instituciones. Es por esta razón, entre muchas otras, que la consulta con los pueblos originarios, y por lo tanto el respeto por sus opiniones y por las cosmovisiones en las que se basan, debe tener lugar de manera obligatoria.

8 La situación desigual en la que se encuentran los pueblos originarios y los aparatos del Estado debería recordarse cada vez que se hacen críticas a esas cosmovisiones y a esas posiciones de los indígenas por su supuesto anticientificismo - de hecho, a veces desde tiendas arqueológicas y antropológicas se acentúa esa desigualdad al presentar, a menudo, el conflicto como una confrontación entre ciencia y religión, entre conocimiento legítimamente producido y superstición o idolatría (ver, por ejemplo, Meigham 2000)ํ․ Lo que ocurre es que, entre otras cosas, se pierde de vista la historia de opresión, subalternización y humillación que los indígenas han padecido a manos de la sociedad dominante. Cuando una comunidad indígena reclama los restos de un antepasado, no se trata, entonces, de creencias ridículas o de supersticiones, sino más bien del ejercicio de un derecho que el resto de la sociedad ha tenido y ellos no: el de disponer de sus muertos de la manera que reclaman tanto sus tradiciones como sus prácticas sociales y culturales del presente. Es por ello, también, que no debería prestarse atención a las posturas de algunos miembros de la comunidad académica cuando sostienen que a los indígenas hay que tratarlos como al resto de la población y, por lo tanto, no otorgarles lo que ellos consideran privilegios -epistémicos y jurídicos. Justamente, es precisamente porque los indígenas nunca fueron tratados de manera igualitaria que hay que legislar hoy para asegurar que esa situación no vuelva a repetirse, al mismo tiempo que para reparar, en la medida de lo posible, el daño que se les ha causado. Todos estos males ocasiona-dos a los indígenas del pasado y del presente son pro-ducto del colonialismo en sus diversas formas, que le da al colonizador una conciencia de tener derecho a todo, por lo cual 
termina por negarle al colonizado el respeto y los derechos que se les dan a otros seres humanos (Riding In 2005:53).

El debate, entonces, no es entre ciencia y religión o entre conocimiento y superstición, sino entre aquellos grupos humanos que gozan de todos los derechos y aquellos que no tienen esa fortuna. Además, en realidad existe amplia evidencia de que las comunidades indígenas no desprecian la ciencia: se valen y se seguirán valiendo de ella para intentar satisfacer sus necesidades vitales, que incluyen no sólo aspectos materiales o económicos (los tan manidos patrones de subsistencia estudiados por la arqueología de inspiración procesual), sino también culturales (por ejemplo, identitarios) y sociales. De ello son un buen ejemplo, por supuesto, los programas de arqueología desarrollados por las comunidades indígenas en los Estados Unidos (ver Begay 1997 sobre el programa arqueológico de los navajo y el importante libro de Watkins 2000, así como un artículo de Sonya Atalay -2006- sobre el tema), pero también los cada vez más frecuentes pedidos de ayuda a los arqueólogos, ya sea para identificar sitios de su pasado o para contribuir a la realización de proyectos de las comunidades que re-quieren de la producción de conocimiento disciplinario (ver el trabajo de Cypress -1997- sobre los seminole y el de Curtoni y Endere -2006- sobre los rankulche de La Pampa). De modo que cada vez queda más claro que los indígenas nada tienen contra la ciencia occidental cuando no se la practica mediante la violación de los derechos humanos de los pueblos originarios. El problema, como decíamos, es otro: una ciencia que no se detiene ante nada y que hace caso omiso, muchas veces, a los derechos de aquellos sujetos que descienden de los seres humanos del pasado remoto cuyos restos están bajo estudio.

Pasemos ahora a una de las preguntas centrales con relación a la restitución de restos humanos: ¿quién puede reclamar qué? En una de las preguntas-disparador que nos enviara el editor de este número, Axel Lazzari, inquiere sobre el asunto de esta manera: "Todos apuntamos al pueblo indígena como sujeto normativo que reclama al resto indígena. Varios textos señalan que sujetos no indígenas reclaman restos indígenas (en

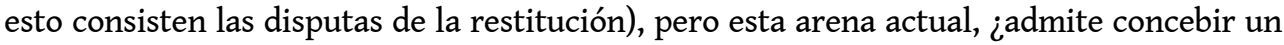
sujeto indígena reclamante de un cadáver no-indígena?" Mi respuesta sería más o menos así: Sí, puedo imaginar a una comunidad indígena, si fuera lo suficientemente fuerte, reclamando el cuerpo de algún no-indígena. Pero eso sólo sería posible si hubiera un diferencial de poder tal que les permitiera acceder a, y disponer exitosamente de, los muertos de otros grupos -o de otros bandos, si es que se trata de algún enemigo del pasado. Pero si esto ocurriera, nada tendría que ver con sus derechos ni con compensación justa alguna: se parecería más bien a un ejercicio indiscriminado de poder -similar al que han estado sufriendo por medio milenio. En el marco actual, no tiene sentido que una comunidad indígena reclame restos no indígenas: la correlación de fuerzas en la sociedad dominante no los favorece.

El tema de la titularidad del discurso y del derecho para hacer un reclamo de devolución de restos humanos indígenas es un asunto complicado en la Argentina, ya que no sólo han ejercido ese derecho los integrantes de comunidades de pueblos originarios, como es costumbre en países como Estados Unidos, que ya vienen elaborando leyes y practicando restituciones o repatriaciones desde hace algo más de dos décadas, sino también otros agentes sociales que no pertenecen a sociedades indígenas. Es el caso, por ejemplo, del pedido de restitución del cráneo (y poncho asociado) del cacique Cipriano Catriel, hecho en primera instancia por dos historiadores locales de Olavarría con el aval de la municipalidad (para este caso, ver Pedrotta y Tancredi 2010)². Sin embargo, la norma en 
el resto del mundo es que los propios miembros de comunidades de pueblos originarios sean los que hagan los reclamos.

En Uruguay, en cambio, la única restitución (en realidad, se trató de una repatriación stricto sensu, pero ya veremos a qué patria se hizo la devolución del individuo) de restos humanos indígenas que ha tenido lugar se llevó adelante sobre todo por parte del Estado nacional.

Se trata del retorno al Uruguay de los restos del cacique charrúa Vaimaca Perú o Pirú (devueltos por el ex-Museo del Hombre), quien fuera parte de un legendario grupo de indígenas conocido, engañosa y erróneamente, como "los últimos charrúas". Estos mal llamados últimos ${ }^{3}$, eran un grupo de indígenas sobrevivientes de la masacre perpetrada por el Estado uruguayo en Salsipuedes (1831), quienes fueron llevados a Francia para ser exhibidos en ferias y en parques de atracciones como exponentes de pueblos salvajes e incivilizados - una práctica que, como se sabe, fue muy común en el siglo XIX (para el tratamiento de la exhibición de indígenas en ferias y museos véanse Anderman 2006, Fernández Bravo 2006, y Anderman y González Stephan 2006, entre otros).

En este caso, si bien los reclamantes iniciales fueron los integrantes de una asociación de descendientes de la nación charrúa llamada $\mathrm{ADENCH}$, lo cierto es que dado el fracaso de sus gestiones ante el museo francés, el proceso de repatriación terminó siendo apropiado por completo por el Estado uruguayo -sí, ese mismo que había llevado a cabo la masacre de Salsipuedes en 1831-, con la cual se dio un paso importante hacia el objetivo genocida de la burguesía criolla. De este modo, la patria a la que el cacique fue regresado termina teniendo muy poco que ver con aquella de la cual se tuvo que ir. Es decir, el retorno de sus restos tuvo lugar a un territorio que él supo habitar, pero que con los años, en un proceso que comenzó con la masacre a la que sobrevivió, se fue transformando de manera irreversible hasta terminar siendo completamente dominado por una cultura, la occidental, que fuera responsable del desmembramiento del mundo indígena en general y del charrúa en particular.

La patria a la que se lo devolvió, entonces, es una que venera como héroes a los asesinos de sus hermanos charrúas, y el lugar concreto en el cual fue depositado es el templo máximo donde descansan las principales figuras de esa patria genocida: el Panteón Nacional del Cementerio Central. En ese lugar donde hoy reposan los restos de Vaimaca Pirú, se encuentran también los de Bernabé Rivera, el exitoso conductor de la masacre de Salsipuedes, pariente cercano del presidente de la República (Fructuoso Rivera) que ordenó la matanza.

16 Una de las particularidades de este caso es que en él los arqueólogos, habituales protagonistas de los debates relacionados con la restitución de restos indígenas, estuvieron por completo ausentes del proceso. La comunidad científica uruguaya no tuvo, entonces, mucha oportunidad de expresar sus opiniones con relación al proceso de retorno del cacique. Es por eso que, exceptuando el puntapié inicial dado por la asociación de descendientes de la nación charrúa, el protagonismo y la agencia se concentraron casi por completo en el Estado uruguayo. Un Estado que, a juzgar por las declaraciones de los más altos representantes del gobierno (véanse las declaraciones del ministro de educación y cultura Mercader en la entrevista que le realizara Emiliano Cotelo - Cotelo 2002-, muy poca idea tenía sobre la historia de Vaimaca y su pueblo, y mucho menos sobre la importancia y el carácter delicado de estos asuntos relacionados con los restos humanos. 
17 Cabe aclarar que si bien en aquella ocasión se involucraron directamente en el proceso los miembros de sólo una de las asociaciones de descendientes de indígenas, los integrantes de la otra asociación pionera en materia de reivindicación y revitalización de la herencia indígena en el Uruguay, INDIA, expresó sus opiniones repetidamente en internet (INDIA s.f.). En esas comunicaciones públicas expresó sus discrepancias con la forma en la que se estaba conduciendo el proceso - algo que no debería sorprendernos- dado que sus relaciones con ADENCH nunca fueron muy buenas (ver para las discrepancias entre INDIA y las asociaciones de descendientes de charrúas las declaraciones de la dirigente de Guyunusa, Ana María Barbosa, en Calvo et al. 2007:82).

Esta falta de unidad de las asociaciones de descendientes de indígenas en el Uruguay explica, en parte, el rumbo que siguieron las cosas. Aunque en realidad hay otro factor que ya mencionamos, además de la debilidad de las asociaciones de descendientes: la no menos débil situación de la comunidad científica y académica uruguaya, que no pudo en ningún momento recibir un mínimo de atención de parte de los dignatarios del gobierno. En el caso comentado aquí, tanto el reclamante natural de los restos indígenas, la asociación de descendientes de la nación charrúa (el grupo que inició todo el proceso), como los arqueólogos, tuvieron que mirar el proceso desde afuera. Todo parece indicar que el único actor fuerte en el Uruguay en estos temas sigue siendo el Estado nacional ${ }^{4}$.

Para que esta situación cambie son necesarias varias cosas, pero sobre todo una: que las actuales comunidades de descendientes de indígenas (que son, al menos hasta donde he podido averiguar, unas siete en el presente) logren un grado de organización que les permita presentar el tema exitosamente en la esfera pública uruguaya. Una vez logrado este objetivo, más allá de que las comunidades sigan o no autodescribiéndose como descendientes y no directamente como indígenas, lo siguiente debería ser buscar un diálogo con esa otra comunidad que quedó excluida de la repatriación de los restos de Vaimaca Pirú: los arqueólogos. No creo equivocarme al sugerir que el futuro de las restituciones en Uruguay dependerá de la buena relación y del diálogo que puedan forjar los pueblos originarios y los académicos. Tal vez de esa manera logren arrebatarle al Estado nacional la exclusividad en materia de agencia en relación a los casos de restitución de restos humanos indígenas. Tal vez de este modo, también, en un país sin legislación indígena, se logre aprobar alguna ley que contemple esa problemática.

A pesar de que el estado de la cuestión en materia de restitución es casi inexistente en Uruguay (la repatriación de Vaimaca Pirú se llevó a cabo en el 2002 y des-de entonces no se ha hablado más del tema) y apenas incipiente en la Argentina, todo parece indicar que en esta última, a pesar de los retrocesos que implican leyes como la de patrimonio del 2003 (que contradice otras leyes que tienen como objetivo promover el respeto a los derechos de los pueblos originarios), se va avanzando poco a poco, al menos en lo legislativo, en una dirección descolonizadora que contribuya a dejar de ver y tratar a los restos indígenas y a su cultura material como meros objetos de estudio y/o como bienes patrimoniales de la nación. Los avances en esa dirección dependerán no sólo de la lucha de los pueblos originarios (sin la cual nada será posible) sino también de una autocrítica, por parte de las disciplinas occidentales, que las ayude a realizar una modificación de sus prácticas $^{5}$. 


\section{BIBLIOGRAPHY}

Anderman, J. (2006). "Espetaculos da diferença: a Exposiçao Antropológica Brasileira de 1882", en: González Stephan, B. y Anderman, J. (Eds.), Galerías del progre-so: museos, exposiciones y cultura visual en América Latina, (pp.151-193). Rosario: Beatriz Viterbo

Anderman, J., González Stephan, B. (2006). “Introducción”, en: González Stephan, B. y Anderman, J. (Eds.), Galerías del progreso: museos, exposiciones y cultura visual en América Latina, (pp.7-25). Rosario: Beatriz Viterbo.

Atalay, S. (2006). Indigenous Archaeology as Decolonizing Practice. American Indian Quarterly 30 (3 \& 4), 280-310.

Begay, R. M. (1997). "The Role of Archaeology on Indian Lands. The Navajo Nation”, en: Swidler, N., Dongoske, K. E., Anyon, R. y Downer, A. S. (Eds.), Native Americans and Archaeologists. Stepping Stones to Common Ground, (pp.161-166). Walnut Creek, London, New Dehli: Altamira Press,

Bieder, R. E. (2000). “The Representation of Indian Bodies in Nineteenth-Century American Anthropology”, en: Misehuah, D. (Ed.), Repatriation Reader. Who Owns American Indian Remains?, (pp. 19-36). Lincoln and London: University of Nebraska Press.

Calvo, L., Lucas, G. y Silva, P. (2007). “Los descendientes de charrúas. Entrevistas. Ana María Barbosa, descendiente charrúa”, en: Arocena, F. y Aguiar, S. (Eds.), Multiculturalismo en Uruguay. Ensayo y entrevistas a once comunidades culturales, (pp.79-84). Montevideo: Trilce.

Cotelo, E. (2002). 169 años después volvió el cacique Vaimaca Perú. Entrevista con Antonio Mercader, Ministro de Educación y Cultura. http://www.espectador. com/perspectiva/ per2002-07-18-9.htm

Curtoni, R. P. y Endere, M. L. (2006). Entre Lonkos y ‘ólogos.' La participación de la comunidad indígena rankülche de Argentina en la investigación arqueológica. Arqueología Suramericana 2 (1), 72-92.

Cypress, B. L. (1997). "The Role of Archaeology in the Seminole Tribe of Florida", en: Swidler, N., Dongoske, K. E., Anyon, R. y Downer, A. S. (Eds.), Native Americans and Archaeologists. Stepping Stones to Common Ground, (pp.156-160). Walnut Creek, London, New Dehli: Altamira Press.

Endere, M. L., Cali, P. y Funari, P. A. (2010). “Arqueología y comunidades indígenas. Un estudio comparativo de la legislación de Argentina y Brasil”, en: Gnecco, C. y Ayala Rocabado, P. (Eds.), Pueblos indígenas y arqueología en América Latina, (pp.273-299). Bogotá: Universidad de los Andes.

Fernández Bravo, A. (2006). “Celebraciones centenarias: nacionalismo y cosmopolitismo en las conmemoraciones de la independencia (Buenos Aires 1910- Río de Janeiro 1922)”, en: González Stephan, B. y Anderman, J. (Eds.), Galerías del progreso: museos, exposiciones y cultura visual en América Latina, (pp.331-372). Rosario: Beatriz Viterbo.

INDIA (s.f.). "Con el respeto y amor del cual siempre hicimos gala” http://members.tripod.com/ indiauy/vaimaca/respeto.htm

Klesert, A. y Powell, S (2000). “A Perspective on Ethics and the Reburial Controversy”, en: Misehuah, D. (Ed.) Repatriation Reader. Who Owns American Indian Remains?, (pp. 200-210). Lincoln and London: University of Nebraska Press. 
Meighan, C. (2000). “Some Scholar's Views on Reburial”, en: Misehuah, D. (Ed.) Repatriation Reader. Who Owns American Indian Remains?, (pp. 190-199). Lincoln and London: University of Nebraska Press.

Pedrotta, V. y Tancredi, M. (2010). "Simbolismo, apropiaciones y conflictos en torno a los reclamos de restitución del cráneo de Cipriano Catriel”, en: Jofré, I. C. (Ed.), El regreso de los muertos y las promesas de oro: Usos y significados de la cultura indígena, (pp.141-168). Córdoba: Encuentro Grupo Editor, Editorial Brujas.

Riding In, J. (2005). “Decolonizing NAGPRA”, en: For Indigenous Eyes Only: A Decolonization Handbook. Santa Fe: School of American Research.

Rodríguez, M. E. (2010). De la "extinción" a la autoafirmación: Procesos de visibilización de la comunidad tehuelche Camusu Aike (Provincia de Santa Cruz, Argentina). Tesis doctoral, Georgetown University http:// cdm15036.contentdm.oclc.org/cgi-bin/showfile. exe?CISOROOT=/ p15036coll3\&CISOPTR=792\&filen ame=793.pdf

Thomas, D. H. (2000). Skull Wars. Kennewick Man, Archaeology, and the Battle for Native American Identity. New York: Basic Books.

Verdesio, G. (2010). "El drama de la restitución de res-tos humanos y sus actores en Uruguay y Argentina: El Estado, los/las arqueólogos/as y las comunidades de Pueblos Originarios”, en: Jofré, I. C. (Ed.), El regreso de los muertos y las promesas de oro: Usos y significados de la cultura indígena, (pp.123-139). Córdoba: Encuentro Grupo Editor, Editorial Brujas

Watkins, J. (2000). Indigenous Archaeology. American Indian Values and Scientific Practice. Walnut Crek, London, New York, Oxford: Altamira Press.

Watkins, J. (2004). Becoming American or Becoming Indian?: NAGPRA, Kennewick Man and Cultural Affiliation. Journal of Social Archaeology 4 (1), 60-80.

\section{NOTES}

1. Para una opinión discrepante y crítica de la posición representada por Meigham, ver Klesert y Powell 2000.

2. En dicho artículo se hace, entre otras cosas, una historia de los pedidos de restitución del cráneo, que en el presente tienen como reclamantes, entre otros, a personas descendientes del cacique por la vía directa.

3. Mal llamados porque con ellos no se extinguió la estirpe, como acreditan las varias asociaciones de descendientes de charrúas que existen en el Uruguay de hoy.

4. Para un tratamiento algo más extenso de este caso véase Verdesio 2010.

5. La carta que acaban de enviar una cantidad importante de arqueólogos y antropólogos al INAI con fecha $1^{\circ}$ de abril de este año (2011), es una señal auspiciosa: la comunidad científica se está ofreciendo a colaborar en la implementación de la ley $\mathrm{N}^{\circ} 25.517$ sobre restitución de restos humanos. El último párrafo de la carta dice: “ofrecemos nuestra colaboración como especialistas en diferentes campos de la antropología y disciplinas afines en la implementación de la Ley No 25.517 y su decreto reglamentario No 701/10, así como en otras problemáticas que Ud. y las comunidades originarias consideren necesario, a los efectos de iniciar un camino de trabajo conjunto que contribuya a que la aplicación de dicha ley se lleve a cabo en un marco de diálogo y respeto mutuo entre todos los actores sociales involucrados." 


\section{AUTHOR}

\section{GUSTAVO VERDESIO}

University of Michigan.

Correo electrónico: verdesio@umich.edu 